\title{
Study of the kidney function remaining in kidney donors and its related factors in transplant center of Imam Khomeini hospital, Urmia
}

\author{
Ehsan Allah Kalteh ${ }^{\circledR}$, Shaker Salari Lak $2^{*(\mathbb{D}}$, Ali Taghizadeh Afshari ${ }^{\circledR}{ }^{\circledR}$, Hamid Reza Khalkhali ${ }^{\circledR}$, Mousa \\ Ghelichi-Ghojogh ${ }^{5}$
}

${ }^{1}$ Faculty of Medicine, Urmia University of Medical Sciences, Urmia, Iran

${ }^{2}$ Department of Public Health, Tabriz Branch, Islamic Azad University, Tabriz, Iran

${ }^{3}$ Nephrology, and Kidney Transplant Research Center, Department of Urology, Imam Khomeini Hospital, Urmia University of Medical Sciences, Urmia, Iran

${ }^{4}$ Department of Epidemiology and Biostatistics, Faculty of Medicine, Urmia University of Medical Sciences, Urmia, Iran ${ }^{5}$ Health Management and Social Development Research Center, Golestan University of Medical Sciences, Gorgan, Iran

\section{Correspondence to:}

Shaker Salari Lak,

Email: salari@iaut.ac.ir

salarilak@yahoo.com

Received: 7 Nov. 2020 Accepted: 14 Dec. 2020 ePublished: 29 Dec. 2020

Keywords: Kidney transplantation, Live donors, Glomerular filtration rate

\begin{abstract}
Introduction: Concerns about the occurrence of premature kidney failure have been expressed a few years after the kidney donation in the donor due to increase in compensatory blood flow in the remaining kidney nephrons.

Objectives: This study aimed to study the kidney function remaining in living kidney donors and its related factors.

Patients and Methods: Data were collected from 30 kidney donors in Imam Khomeini hospital in Urmia and evaluated using SPSS-22 software.

Results: The mean duration of nephrectomy was $36.36 \pm 6.22$ years. The mean serum creatinine was significantly increased at the time of examination than before donation, and the glomerular filtration rate (GFR) decreased significantly $(P<0.001)$. Male donors $(P=0.025)$ and donors who did not have relative relationship with the recipient $(P=0.44)$ had better kidney function. The renal function at the time of examination was $74.86 \%$ amount before donation. The glucose tolerance test $(\mathrm{mg} / \mathrm{dL} 2$ hours) of the donors increased significantly at the time of the study compared to the time before donation $(P=0.049)$.

Conclusion: The remaining kidney function of the donors has decreased significantly seven years after donation. It seems that kidney donors need more time to excrete excess glucose, so they are far from being over-carbohydrate.
\end{abstract}

Introduction

Cadaver is an important source of transplantation organ supply (1), but the shortage of dead kidney donors (2) and achieving better results by kidney transplantation from living donors have led to an increase in number of living kidney donors (3). There is a significant geographical variation in the annual number of living kidney donors. In 2006, the highest annual transplantation rate per million population (pmp) of living kidney donors was $32 \mathrm{pmp}$ in Saudi Arabia, pmp $=29$ in Jordan, $\mathrm{pmp}=26$ in Iceland, and $\mathrm{pmp}=23$ in Iran (4). The higher kidney transplantation rate from living donors nationwide along with rising prevalence of end-stage kidney diseases have increased the tendency to accurately estimate the long-term risks of kidney donation (5). Studies conducted

\section{Key point}

In a study on 30 kidney donors in Urmia, with mean duration of nephrectomy of $36.36 \pm 6.22$ years, we found renal function of the donors has decreased significantly seven years after donation therefore kidney donors need to be followed up after a kidney donation.

during 10 to 20 years after donation indicate that despite a $50 \%$ decrease in renal mass after unilateral renal nephrectomy, the renal plasma flow (RPF) and glomerular filtration rate (GFR) remain constant in about $70 \%$ of the preoperative value, indicating the higher rates of RPF, GFR and renal mass (6). Therefore, there are concerns about possible risk of early kidney failure a few years after kidney donation in donors because of compensatory increases in blood flow and circulation in each of the residual (6-9).

Copyright (C) 2020 The Author(s); Published by Society of Diabetic Nephropathy Prevention. This is an open-access article distributed under the terms of the Creative Commons Attribution License (http://creativecommons.org/licenses/by/4.0), which permits unrestricted use, distribution, and reproduction in any medium, provided the original work is properly cited. 
Some studies on complications of kidney donors have indicated changes in renal functions $(8,10,11)$. A number of retrospective studies have also reported excellent results in terms of GFR (12) for living kidney donors. Studies on the complications of living kidney donors have had contrast results.

\section{Objectives}

There are too few studies in Iran as a leading country on the kidney transplantation (13); hence, the present study aimed to determine the residual renal functions of kidney donors and their effective factors in the transplantation center of Imam Khomeini hospital in Urmia.

\section{Patients and Methods}

\section{Study patients}

In a retrospective cohort study on 1906 cases of kidney donation nephrectomy performed in Imam Khomeini hospital of Urmia from 1997 to the end of 2014 and after excluding cases, who did not have the Iranian citizenship [85 cases $(4.4 \%)]$, the donors were dead kidney donors [108 cases $(5.6 \%)]$ or had incomplete records [250 cases (13.1\%)]. From the rest of them [1463 cases (76.7\%)], 299 cases were living in the west Azerbaijan, had contact numbers during the donation and were included in the study if they were alive during the study. From 299 cases, 30 ones were contacted. The demographic, anthropometric, and biochemical characteristics of donors before donation (based on the data contained in medical records) were recorded and completed at the second stage of the prementioned variables (after donation and duration of the study) through questionnaires and measurement. Written informed consent was obtained from participants to collaborate in the study. The remaining list of individuals to get the correct phone number from telecommunication company of west Azerbaijan province was referred to the provincial public prosecutor's office and as the prosecutor opposed it, it was impossible to make any contact with them.

The GFR was calculated based on the proposed valid equation of the modification of diet in renal disease $\left(\right.$ MDRD) study $\left(186.3 \times \mathrm{Scr}^{-1.154} \times\right.$ Age $\left.^{-0.203} \times 1.212 \times 0.742\right)$ (0.742 for female gender, 1.212 for black person, age in year, and Scr in $\mathrm{mg} / \mathrm{dL}$ ) which was very reliable and measured the GFR with accurate estimation.

\section{Ethical issues}

Human rights were respected in accordance with the Helsinki Declaration 1975, as revised in 1983. The ethical committee of Urmia University of Medical Sciences (ethical code: IR.Goums.REC.1395.219) confirmed the study. The informed consent was taken from the patients. This study was extracted MSc, from thesis of Ehsan Allah Kalteh at this university.

\section{Statistical analysis}

Paired $t$ test and Wilcoxon tests were used to compare quantitative variables before donation and study time; and Spearman correlation and Mann-Whitney $U$ tests were utilized to investigate the relationships of quantitative and qualitative variables with GFR. In all cases of analysis with SPSS-22, $P$ value of less than 0.05 was considered to be significant.

\section{Results}

The percentages of male donors, left kidney donors, and donors with no relative kinship with recipients were 27 cases (90\%), 28 (93.3\%) and $26(86.7 \%)$ respectively. The mean age at the time of donation and evaluation and duration of nephrectomy were $30.66 \pm 6.64$ years, $38 \pm 9.48$ years, and $7.36 \pm 4.62$ years respectively.

Mean serum creatinine $(\mathrm{mg} / \mathrm{dL})$ and GFR $(\mathrm{mL} / \mathrm{min} / 1.73$ $\mathrm{m}^{2}$ ) showed a significant increase and decrease than the preoperative nephrectomy respectively $(P<0.001)$. GFR during the study was about $74.86 \%$ higher than the predonation. Fasting blood sugar $(\mathrm{mg} / \mathrm{dL})$ of donors did not change significantly during the study compared to the pre-donation $(P=0.742)$, however their glucose tolerance (mg/dL 2 hours) showed a statistical significant increased $(P=0.049$; Table 1$)$.

Male donors $(P=0.025)$ and donors with no relative kinship with recipients $(P=0.044)$ had better residual renal functions. The residual renal function decreased with increasing age of donation $(\mathrm{r}=-0.56$ and $P<0.001)$ and examination age $(r=-0.64$ and $P<0.001$; Tables 2 and 3$)$.

\section{Discussion}

In the present study, serum creatinine levels significantly increased compared to the pre-donation. The results were consistent with results of some previous studies, but they did not increase significantly in some studies $(11,13$ 15). The kidneys play important roles in the blood sugar homeostasis. When blood sugar increases in the blood flow, the excess glucose enters into the urine to reduce the blood sugar. During fasting or decreasing plasma glucose, the kidneys help maintain the blood sugar by gluconeogenesis, glycogenolysis, and increasing sodium/potassium pump activity, and ATPase, and expression of sodium-glucose

Table 1. Comparison of mean biochemical findings before nephrectomy and during the study

\begin{tabular}{|c|c|c|c|}
\hline Results & Before nephrectomy & During the study & $P$ value \\
\hline Serum creatinine $(\mathrm{mg} / \mathrm{dL})$ & $0.92 \pm 0.15$ & $1.17 \pm 0.2$ & $<0.001$ \\
\hline Fasting blood sugar (mg/dL) & $92.2 \pm 14.79$ & $91.13 \pm 14$ & 0.742 \\
\hline Glucose tolerance (mg/dL 2 hours) & $90.93 \pm 15.89$ & $111.23 \pm 39.69$ & 0.049 \\
\hline GFR $\left(\mathrm{mL} / \mathrm{min} / 1.73 \mathrm{~m}^{2}\right)$ & $102 \pm 16.5$ & $74.95 \pm 18.63$ & $<0.001$ \\
\hline
\end{tabular}


Table 2. Relationships of age, distance from nephrectomy, and clinical results of donors with GFR during the examination

\begin{tabular}{lcc}
\hline Variable & $\begin{array}{c}\text { Correlation } \\
\text { coefficient }(\mathbf{r})\end{array}$ & $\boldsymbol{P}$ value \\
\hline Age at the time of donation & $0.568-$ & 0.001 \\
\hline Age at the time of study & $0.654-$ & $<0.001$ \\
Distance from nephrectomy & $0.324-$ & 0.08 \\
\hline Duration of hospitalization for surgery & $0.238-$ & 0.205 \\
Systolic blood pressure at the time of donation & 0.12 & 0.528 \\
Diastolic blood pressure at the time of donation & $0.072-$ & 0.707 \\
Systolic blood pressure at the time of study & 0.042 & 0.824 \\
Diastolic blood pressure at the time of study & 0.039 & 0.837 \\
\hline
\end{tabular}

Table 3. Relationships demographic variables with GFR at the time of the study

\begin{tabular}{lllll}
\hline Variable & Grouping & No. $(\%)$ & Mean \pm SD & P value \\
\hline \multirow{2}{*}{ Gender } & Men & $27(90)$ & $76.73 \pm 18.8$ & \multirow{2}{*}{0.025} \\
& Women & $3(10)$ & $58.99 \pm 3.6$ & \\
\multirow{2}{*}{ Kidney donation side } & Right & $2(6.7)$ & $66.02 \pm 31.23$ & \multirow{2}{*}{0.868} \\
& Left & $28(93.3)$ & $75.59 \pm 18.17$ & \\
\multirow{2}{*}{$\begin{array}{l}\text { Relationship with the } \\
\text { receiver }\end{array}$} & Unrelated & $26(86.7)$ & $76.85 \pm 19.16$ & \multirow{2}{*}{0.044} \\
\hline
\end{tabular}

cotransporter-2 (SGLT2). In healthy adults, 5.5-mmol daily glucose excretes in the urine through canals and the glomerulus. However, 99\% of glucose is absorbed through the bloodstream. However, the capacity of glucose reabsorption is limited in urine. In renal disease or kidney donors, fasting blood glucose cannot be as a kidney damage index, and thus the glucose tolerance test should be used to detect kidney damage (16-18). Results of the present study indicated that fasting blood sugar did not change significantly before and after donation, but the glucose tolerance test indicated a significant increase during the study compared to the donation time. It seems that kidney donors need more time for excretion of excess glucose into the urine. Therefore, those who donate kidneys should not eat a high-carbohydrate diet.

On average, GFR calculated in donors in different studies is about $75-85 \%$ of similar values in people with two kidneys (13). In the present study, the GFR was $74.86 \%$ during the study compared to the pre-donation. In a study by Ibrahim et al, it was $76 \%$ that was a compensatory increase in residual rental GFR associated with younger age during donation, longer time after donation, and greater GFR during donation (3). GFRs of donors were affected by various factors. In a multivariate analysis by Tsai, older age during donation and follow-up were risk factors of the GFR (10). In a study by Costa-Moreira et al, there was no evidence suggesting a rapid decline of GFR, rather than effects of age, after its initial decline (12). In a study by Meier-Kriesche et al, the higher GFR during the donation was the only significant factor in reducing the GFR (11). In our study, male gender and no relative kinship with recipients had significant and direct association with GFR; however, age during donation and examination had negative statistical correlation with it. It should be noted that the ability of kidneys to respond to acute changes in fluid and electrolyte decreases at older age; and the elderly patients might have unusual and nonspecific symptoms of renal dysfunction and lack of fluid and electrolyte balance (19). Inviting donors to study and follow up is very difficult. Donors, who are not tracked, may have dire consequences. Therefore, the actual incidence of consequences cannot be determined. Donors need eligibility criteria for donations; hence, comparing them to the general public cannot be valid. No control group was selected in the present study due to the small number of donors and limited references of study. In general, results indicated that renal function in the present study and previous studies was maintained at an acceptable level and did not progressively decrease. Due to the small sample size and the necessity of using bivariate statistical tests, the effect of increasing age on renal function and the inability to separate age effects from effects of interval between donation and time of renal function re-evaluation as well as the lack of appropriate control group, our study results indicated differences between two periods and should not be considered as a final result.

\section{Conclusion}

The results of this study showed that residual renal function of donors decreased significantly about seven years after the donation. Kidney transplantation centers need to take all care measures by setting up an electronic registration system to monitor changes in health. Although the residual renal function of donors significantly decrease, studies should follow up a greater number of donors with a proper control group.

\section{Limitations of the study}

It was a single-center study. All donors did not respond to our call.

\section{Acknowledgments}

The authors would like to thank the vice chancellor for research and technology for financial support and especially the physicians and staff of kidney transplant ward of Imam Khomeini hospital.

\section{Authors' contribution}

EAK and MGG were the main investigators, collected the data and wrote the first draft. SS, HN, ATA AND HRK designed the study, and also read and corrected the draft. All authors read and signed the final manuscript.

\section{Conflicts of interest}

The authors declare no conflict of interest.

\section{Ethical considerations}

Ethical issues (including plagiarism, data fabrication, double publication) have been completely observed by the authors. 


\section{Funding/Support}

This project was funded by the research deputy of Urmia University of MEDICAL SCIENCES (Grant \#950923220).

\section{References}

1. Ellison MD, McBride MA, Taranto SE, Delmonico FL, Kauffman HM. Living kidney donors in need of kidney transplants: a report from the Organ Procurement and Transplantation Network. Transplantation. 2002;74:1349-51.

2. Kasiske BL, Anderson-Haag T, Ibrahim HN, Pesavento TE, Weir MR, Nogueira JM, et al. A Prospective controlled study of kidney donors: baseline and 6-month follow-up. Am J Kidney Dis. 2013;62:577-86.

3. Ibrahim HN, Foley R, Tan L, Rogers T, Bailey RF, Guo H, et al. Long-Term Consequences of Kidney Donation. N Engl J Med. 2009;360:459-69.

4. Diane Horva L, Shariff SZ, Garg AX. Global trends in the rates of living kidney donation. Kidney Int. 2009;75:1088-98.

5. Thieme F, Janoušek L, Králová A, Čejková S, Králová Lesná I, Poledne R, Froněk J. Adipose tissue collection from a living kidney donor; an experimental model for the research of atherosclerosis. Rozhl Chir. 2019;98:476-480. doi: 10.33699/ PIS.2019.98.12.476-480.

6. Savadgar MS. Surgical Complication in 350-kidney transplant kidney transplant center Taleghani Hospital in Urmia city. [dissertation]. Urmia: School Med, Univ Med Sci; 1994.

7. Gibney EM, King AL, Maluf DG, Garg AX, Parikh CR. Living kidney donors requiring transplantation: focus on African Americans. Transplantation. 2007;84:647-9.

8. De Broe ME, Gharbi MB, Zand $M$, Elseviers $M$. Why overestimate or underestimate chronic kidney disease when correct estimation is possible? Nephrol Dial Transplant. 2017;32:ii136-41. doi: 10.1093/ndt/gfw267.

9. Hirose T, Hotta K, Iwami D, Harada H, Morita K, Tanabe T, et al. Safety and efficacy of retroperitoneoscopic living donor nephrectomy: comparison of early complication, donor and recipient outcome with hand-assisted laparoscopic living donor nephrectomy. J Endourol. 2018;32(12):1120-4.

10. Tsai SF, Shu KH, Ho HC, Wu MJ, Cheng CH, Lian JD, et al. Longterm outcomes of living kidney donors over the past 28 years in a single center in Taiwan. Transplant Proc. 2012;44:-39-42.

11. Meier-Kriesche HU, Port FK, Ojo AO, Rudich SM, Hanson JA, Cibrik DM, et al. Effect of waiting time on renal transplant outcome. Kidney Int. 2000;58:1311-7.

12. Costa-Moreira P, Vilas-Boas F, Teixeira Fraga A, Macedo G. Particular aspects of gastroenterological disorders in chronic kidney disease and end-stage renal disease patients: a clinically focused review. Scand J Gastroenterol. 2020;55:129-138. doi: 10.1080/00365521.2020.1722217.

13. Park JS, Yoon MG, Na JC, Lee $\mathrm{HH}$, Yoon $\mathrm{YE}$, Huh $\mathrm{KH}$, et al. Investigation of systolic blood pressure, diastolic blood pressure, and pulse pressure in living kidney donors after donor nephrectomy. Transplant Proc. 2019;51:2533-8.

14. Abdellaoui I, Azzabi A, Sahtout W, Sabri F, Hmida W, Achour A. Short- and long-term follow-up of living kidney donors. Saudi J Kidney Dis Transpl. 2019;30:401-20. doi: 10.4103/13192442.256848 .

15. Ramcharan T, Matas AJ. Long-term (20-37 years) follow-up of living kidney donors. Am J Transplant. 2002; 2: 959-964.

16. Jia $T$, Riserus $U, X u H$, Lindholm B, Arnlov J, Sjogren $P$, et al. Kidney function, $\beta$-cell function and glucose tolerance in older men. J Clin Endocrinol Metab. 2015;100:587-93.

17. Rufino $\mathrm{MI}$, Barbero $\mathrm{P}$, Hernandez D, Torres A, Lorenzo V. Usefulness of oral glucose tolerance test (OGTT) in output patients with advanced chronic renal failure (CRF). Nefrologia. 2007;27:30-7.

18. Merlin C Thomas. Renal effects of dapagliflozin in patients with type 2 diabetes. Ther Adv Endocrinol Metab. 2014;5:53-61.

19. Schlanger LE, Bailey JL, Sands JM. Electrolytes in the aging. Adv Chronic Kidney Dis. 2010;17:308-19. doi: 10.1053/j. ackd.2010.03.008. 